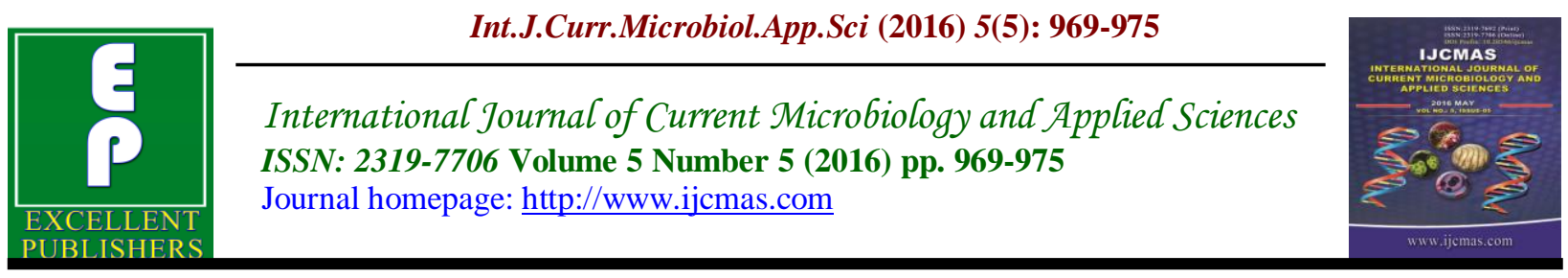

Original Research Article

http://dx.doi.org/10.20546/ijcmas.2016.504.110

\title{
Validity of TNFRII Polymorphism in Susceptibility and Severity of Rheumatoid Arthritis Iraqi Patients
}

\author{
Wasnaa J. Mohammed ${ }^{1}$, Mohammed Sh. Jabur ${ }^{2 *}$, Nizar Ab. Jasim ${ }^{3}$ and Basim Sh$^{4}$ \\ ${ }^{1}$ College of Nursing, Baghdad University, Iraq \\ ${ }^{2}$ College of Health and Medical Technology, Iraq \\ ${ }^{3}$ College of Medicine, Baghdad University, Iraq \\ ${ }^{4}$ College of Medicine, Al-Mustansiriya University, Iraq \\ *Corresponding author
}

\begin{abstract}
A B S T R A C T
Keywords

Rheumatoid arthritis,

TNFRII

polymorphism,

Susceptibility,

Severity.

\section{Article Info}

Accepted:

25 March 2016

Available Online:

10 April 2016

Tumor necrosis factor (TNF $\alpha$ ) plays an important role in autoimmune pathogenesis and is the main therapeutic target of rheumatoid arthritis (RA). TNF $\alpha$ signals via 2 receptors, TNF type 1(TNFRI) and (TNFRII) signaling are mainly activated by membrane TNF ( $\mathrm{m} T \mathrm{TN} \alpha$ ). The present study was aimed to investigate the role of TNF $-\alpha$ RII gene polymorphisms in susceptibility and severity of rheumatoid arthritis. Fifty RA patients and 50 apparently healthy controls were enrolled in the study. Genotyping of $196 \mathrm{M} / \mathrm{R}$ polymorphism of TNFRII gene was determined by PCR-RFLP. Results were suggested that TNFRII196M/R polymorphism were associated with RA susceptibility. There was a significant difference in the genotype frequencies polymorphism of the TNFRII 196M/R between control and RA patients $(\mathrm{p}<0.05)(\mathrm{p}<0.01)$.
\end{abstract}

\section{Introduction}

Rheumatoid arthritis is one of the most common systemic autoimmune diseases. RA characterized by chronic inflammation in the synovium, resulting in progressive destruction of joints and cartilage. Although the pathophysiology of RA has not been completely understood yet, increasing numbers of cytokines have been found to be involved in RA pathology (1). Several detection methods (ELISA, immunohistochemistry) have identified TNF- $\alpha$ and IL-1 as major players in the network of cytokines, notably directly expressed at the disease site in joint fluid tissue. Recently, more cytokines, including IL-6, IFN- $\gamma$, GM-CSF, IL-17, IL-21, IL-18 and IL-15, have also been found to be involved in the RA pathology(2).

TNFis considered as one of the main mediators of joint inflammation in RA. A number of experimental studies have demonstrated that it plays a significant role in local joint damage and systemic bone 
loss, as it increases osteoclast (OC) mediated bone resorption $(3,4)$. TNF enhances OC activity by directly promoting OC differentiation of bone marrow macrophages exposed to permissive levels of RANK-ligand (RANKL), ${ }^{1}$ by stimulating RANKL expression by $\mathrm{T}$ and $\mathrm{B}$ lymphocytes, by promoting stromal RANKL production of osteoblasts (OB), and by enhancing RANK and IL-1 expression of myeloid OC precursors $(5,6)$.

TNF- $\alpha$ is a multifunctional cytokine with potent pro - inflammatory effects through stimulation of Tcell, up regulation of proteolytic enzymes, and increase secretion of prostaglandin and chemokines $(7,8)$.

TNF- $\alpha$ is a major factor involved in the RA inflammatory state. The TNF- $\alpha$ gene is a member of TNF super family located within the class II region of the human MHC on chromosome 6p21. Promoter polymorphisms within $\mathrm{TNF}-\alpha$ genes have been reported in inflammatory and infectious diseases(9). Promoter polymorphisms at TNF- $\alpha$ have been associated with disease susceptibility, or severity of joint damage and autoantibody production in RA in different populations. Several TNF- $\alpha$ polymorphisms have been studied such as genotype 308A/G polymorphisms because of their association with increased TNF- $\alpha$ secretion and their implication in susceptibility of several autoimmune disease such RA (10). The pleiotropic biological activities of TNF- $\alpha$ are mediated by its binding to TNF receptors (TNFR) Type I and II. Both are expressed in synovial fluid and cartilage in RA patients. Several studies, upon the gene polymorphism at $169 \mathrm{M} / \mathrm{R}$ in TNFR type II showed that, this polymorphism has been implicated in severity in RA $(9,10)$. Currently the study was done to evaluate the association of TNFRII polymorphisms in development and severity of RA in Iraqi patients compared to control healthy individuals.

\section{Subjects and Methods}

The study included 50 Iraqi RA patients. These patients diagnosed according to the criteria of American College of Rheumatology. Subjects included in the study underwent routine biochemical blood analysis and x-rays of the hands and feet. The evaluation of subjects included physical examination, with particular focus on the pattern of joint involvement, the presence of nodules and other extra-articular features (such as vasculitis, anemia, subcutaneous nodules, vasculitis manifestation, organ involvement, and laboratory features such as rheumatoid factor (RF). Disease activity has been determined on the basis of defined parameters (the number of swollen and tender joints, ESR, Health Assessment Questionnaire (HAQ), C reactive protein (CRP) and a global physician's assessment. Disease severity has been determined on the basis of defined parameters (RF and X-ray erosion). Patients deemed to have an erosive arthropathy if one or more definitive erosions appear in any of the peripheral joints that have been identified to be predictive of disease progression. Fifty healthy Iraqi adult male and female women used as a healthy control group. They never had any signs or symptoms of RA, other arthritis, or joint diseases (pain, swelling, tenderness, or restriction of movement) at any site based on their medical history and examination.

\section{Collection of Blood Samples}

Eight $\mathrm{mL}$ of venous blood was drawn from each individual of the two groups under complete aspect condition after an overnight fasting. Three $\mathrm{mL}$ of blood was collected in 
EDTA containing tube for separation of peripheral blood mononuclear cells (PBMCs) for determination of TNFRII genotypes. The other $3 \mathrm{ml}$ of blood were collected in anticoagulant-free tubes used for separation of serum to detect RA and CRP, ACCP levels. Two mL was collected in ESR tube.

\section{Methods}

\section{Biochemical Analysis}

Blood samples were drawn from all subjects after an overnight fasting. Sera were separated immediately and stored at $-20^{\circ} \mathrm{C}$. CRP assayed by high-sensitivity enzymelinked immunosorbent assay (ELISA). RF and ACCP assayed by enzyme linked immunoassay.

\section{DNA Extraction}

Genomic DNA was extracted from EDTA whole-blood sample using a spin column method according to the protocol (ReliaPrep Blood g DNA Miniprep System, Promega).

\section{Amplification of TNFRII Polymorphism}

The subjects were genotyped for TNFRII exon6 polymorphism by polymerase chain reaction - restriction fragment length polymorphism (PCR - RFLP). PCR reaction was carried out in a $25 \mathrm{ul}$ reaction containing 12.5ul of Green Master Mix, 1ul of $10 \mathrm{pmol} / \mathrm{ul}$ of each primer, 5ul of DNA template and the volume was completed to 25ul using nuclease-free water. Master mix consist of dNTPs, Mgcl2, Taq polymerase.

For TNFRII polymorphism, the region surrounding the polymorphism was amplified with following forward primer. 5ACTCTCCTATCCTGCCTGCT 3 and reverse primer5 TTCTGGAGTTGGCT GCGTGT 3. PCR was performed at initial step at $95^{\circ} \mathrm{Cfor} 4 \mathrm{~min}$, followed by denaturation step at $95^{\circ} \mathrm{C}$ for $30 \mathrm{sec}$, annealing step at $58^{\circ} \mathrm{C}$ for $30 \mathrm{sec}$, extension step at $72^{\circ} \mathrm{C}$ for $1 \mathrm{~min}$ and repeat step $2-4$ for 34 cycles. After that extension at $72^{\circ} \mathrm{C}$ for $10 \mathrm{~min}$. holding at $4^{\circ} \mathrm{C}$.

PCR products were resolved on $1 \%$ agarose gel. The gel was prepared by dissolving $1 \mathrm{~g}$ of agarose in $100 \mathrm{ml}$ of $1 \mathrm{x}$ TAE buffer using a microwave oven. The mixture was left to cool to about 55-60 C before a 1ul of $10 \mathrm{mg} / \mathrm{ml}$ of ethidium bromide was added. It was then poured into the electrophoresis tank, secure the combs in place, and left to cool and solidify for about 30min. After the gel was set, the combs were removed carefully and the tank was placed in the electrophoresis system containing running buffer consisting of $1 x$ TAE. The buffer was poured until it covered the gel for about 1-2 mm. Five $\mu l$ of each PCR product along with the negative control and a 100 bp DNA ladder were loaded into the wells, the system cover was then put into place and the system was turned on. The gel is left to run for $90 \mathrm{~min}$ with a 100volt/50 mAmp current. Following electrophoresis, visualization was conducted with a UV trans illuminator and the image was captured by digital camera (Canon, US). This camera has the appropriate filter and a suitable program for illumination of EtBr-stained gels.

Twenty microliter PCR products were digested with $0.5 \mathrm{ul}$ of NlaIII enzyme and incubated in a thermal cycler at $65^{\circ} \mathrm{C}$ for $3 \mathrm{~h}$. Digested products were resolved on $1.5 \%$ agarose gel.

\section{Statistical Analysis}

The statistical analysis system- SAS (2012) program was used to effect of difference factors in study parameters. Chi-square test was used to significant compare between 
percentage and least significant difference LSD test was used to significant compare between means in this study.

\section{Results and Discussion}

The frequencies of the MM, MR, RR genotypes of TNFRII gene polymorphism were $52 \%, 42 \%$, and $6 \%$ in controls, $60 \%$, $32 \%$, and $16 \%$ in RA patients. There was significant difference in the genotypes frequencies polymorphism of the TNFRII 196MR polymorphism between control and RA group $(p<0.05)(p<0.01)$.

Genotype was associated with a significantly increased $(\mathrm{p}<0.01)$ risk of $\mathrm{RA}$ group as compared to control.

The frequencies of the $\mathrm{M}$ and $\mathrm{R}$ allele of TNFRII gene polymorphism were $0.73,0.27$ in controls and $0.76,0.24$ in RA patients.

Table.1 Compare between Patients and Control in Study Parameters

\begin{tabular}{|c|c|c|c|c|c|}
\hline \multirow[t]{2}{*}{ Group } & \multirow[t]{2}{*}{ No. } & \multicolumn{4}{|c|}{ Mean \pm SE } \\
\hline & & ESR & CRP & RF & ACPA \\
\hline Patients & 50 & $52.96 \pm 3.68$ & $38.39 \pm 4.31$ & $\begin{array}{c}168.87 \pm \\
31.62\end{array}$ & $\begin{array}{c}114.85 \pm \\
21.06\end{array}$ \\
\hline Control & 50 & $10.44 \pm 0.74$ & $16.49 \pm 2.51$ & $4.96 \pm 0.71$ & $1.71 \pm 0.13$ \\
\hline LSD value & ב--- & $7.459 * *$ & $9.918 * *$ & $62.766 * *$ & $41.801 * *$ \\
\hline
\end{tabular}

Table.2 Distribution of Sample Study according to Genotype of TNFII Gene

\begin{tabular}{|c|c|c|c|c|c|}
\hline \multirow[t]{2}{*}{ Genotype } & \multicolumn{2}{|c|}{ Patients } & \multicolumn{2}{|c|}{ Control } & \multirow{2}{*}{$\begin{array}{c}\text { Chi-square } \\
\left(\chi^{2}\right)\end{array}$} \\
\hline & No. & $\%$ & No. & $\%$ & \\
\hline $\mathrm{MM}$ & 30 & 60.00 & 26 & 52.00 & $4.633 *$ \\
\hline MR & 16 & 32.00 & 21 & 42.00 & $4.953 *$ \\
\hline RR & 4 & 16.00 & 3 & 6.00 & $4.953 *$ \\
\hline Total no. & 50 & $100 \%$ & 50 & $100 \%$ & \\
\hline $\begin{array}{c}\text { Chi-square } \\
\left(\chi^{2}\right)\end{array}$ & --- & $10.438 * *$ & --- & $11.307 * *$ & --- \\
\hline
\end{tabular}

Table.3 Allele Frequency of TNFII Gene in Patients and Control

\begin{tabular}{||c||c||c|}
\hline Genotype & Patients & Control \\
\hline \hline $\mathrm{M}$ & 0.76 & 0.73 \\
\hline $\mathrm{R}$ & 0.24 & 0.27 \\
\hline \hline Total & $1(100 \%)$ & $1(100 \%)$ \\
\hline
\end{tabular}


Table.4 Relationship between Genotype of Exon6 TNFII Gene and Study Parameters of Patients

\begin{tabular}{|c||c||c|c|c|c||}
\hline \multirow{2}{*}{ Genotype } & \multicolumn{1}{|c||}{ No. } & \multicolumn{4}{c|}{ Mean \pm SE } \\
\cline { 3 - 6 } & & ESR & CRP & RF & ACPA \\
\hline \hline MM & 30 & $33.75 \pm$ & $30.02 \pm$ & $75.24 \pm$ & $55.14 \pm$ \\
& & 4.08 & 3.65 & 20.71 & 14.63 \\
\hline \hline MR & 16 & $26.34 \pm$ & $24.34 \pm$ & $101.33 \pm$ & $71.52 \pm$ \\
& & 27.38 & 4.50 & 32.33 & 23.26 \\
\hline \hline RR & 4 & $43.42 \pm$ & $23.19 \pm$ & $104.10 \pm$ & $13.42 \pm$ \\
& & 11.96 & 9.86 & 96.63 & 11.47 \\
\hline \hline LSD value & --- & $15.631 *$ & $19.174 \mathrm{NS}$ & $55.63 \mathrm{NS}$ & $23.931 *$ \\
& & & & \\
\hline
\end{tabular}

Table.5 Relationship between Genotype of Exon6 TNFII Gene and Study Parameters of Control

\begin{tabular}{|c|c|c|c|c|c|}
\hline \multirow[t]{2}{*}{ Genotype } & \multirow[t]{2}{*}{ No. } & \multicolumn{4}{|c|}{ Mean \pm SE } \\
\hline & & ESR & CRP & $\mathrm{RF}$ & ACPA \\
\hline $\mathrm{MM}$ & 26 & $9.76 \pm 1.11$ & $19.76 \pm 3.57$ & $4.55 \pm 0.84$ & $1.82 \pm 0.24$ \\
\hline$\overline{\mathrm{MR}}$ & 21 & $10.47 \pm 0.98$ & $13.99 \pm 3.91$ & $5.51 \pm 1.36$ & $1.60 \pm 0.09$ \\
\hline RR & 3 & $16.00 \pm 3.05$ & $5.76 \pm 1.82$ & $4.65 \pm 1.37$ & $1.50 \pm 0.08$ \\
\hline LSD value & --- & $5.549 *$ & $18.96 \mathrm{NS}$ & $5.341 \mathrm{NS}$ & $1.0108 \mathrm{NS}$ \\
\hline
\end{tabular}

Tumor necrosis factor $(\mathrm{TNF} \alpha)$ is a pleiotropic cytokine that plays an important role in mediating various immune functions including inflammation, the regulation of apoptosis and necrosis, and induction of cytotoxicity(11).TNF $\alpha$ is capable of eliciting a variety of different immune responses by signalling via two types of membrane-bound receptors, type I (CD120a, TNFRSF1A) and type II (CD120b, TNFRSF1B). The main function of TNFRII is proliferation induction in addition to apoptosis induction via a DD-independent mechanism (12)Differences in the levels of receptor expression can also be affected by TNF $\alpha$ receptor gene polymorphisms. A considerable number of SNPs located within the promoter region of TNF-TNFR super family gens can affect regulation by significantly impacting levels of gene expression (13). The presence of certain alleles within promoter regions of cytokine receptor genes can influence gene transcription rates and mRNA stability resulting in increased or decreased levels of the synthesized protein. The SNPs analyzed during the course of this study were located within the TNF $\alpha$ receptor gene types I and II promoter regions and are therefore likely to affect TNFRs expression levels (14).

It may be speculated that polymorphism within the TNFR genes could alter binding of ligands such as TNF- $\alpha$ or cleavage enzymes, thereby leading to an inappropriate inflammatory response due to excessive 
circulating TNF- $\alpha$, and hence contributing to RA susceptibility(15).

The result of the present study of the TNFRII polymorphism in RA patients and controls demonstrated that there was a significant difference $(p<0.01)$ in the genotypes frequencies polymorphism is evaluate the possible association between the presence of the TNFRII $196 \mathrm{M} / \mathrm{R}$ genotype and susceptibility to rheumatoid arthritis and there was significant difference $(p<0.05)$ in frequency of genotype and study parameters ESR and ACPA in patients of RA, these parameters refers to disease activity and severity.

These results agreewith Hussein et al. 2014 (9), study which who that the TNFRII 196 $\mathrm{M} / \mathrm{R}$ genotype appear to be significantly associated with RA, and the functional severity $(9,10)$. Recently, TNFRII 196M/R transfectants have been shown to be associated with higher production of IL -6 , which play role in the pathogenesis of RA. In addition, this result agree with Goeb et al., which show the possible association between presence of TFRII $196 \mathrm{M} / \mathrm{R}$ and rheumatoid diagnosis and prognosis.

The frequencies of the TNFRII 196M/R observed in the present study were not different from the previously reported frequencies in the Saudi Arabia, Egypt, UK and the French RA populations $(9,10,16,17)$.

In contrary shibue et al., 2000 reported that the TNFRII position 196 polymorphism (TNFRII196M/R) was not significantly associated with RA in Japanese patients (18).

In conclusion the findings of this study suggested that TNFRII $196 \mathrm{M} / \mathrm{R}$ associated with susceptibility and severity of rheumatoid arthritis in Iraqi population according to the frequencies of the genotypes and relation with disease activity and severity parameters.

\section{References}

1.Alicia Santossavio, Anacecilia Machado Diaz,Araceli Chico Capote et al. (2015) Differential expression of proinflammatory cytokines IL-15R alpha, IL-15, IL-6 and TNF alpha in synovial fluid from rheumatoid arthritis patients. BMC Musculoskeletal Disorders. 16; 51:12891-0516-3.

2.McInnes IB， Schett G.(2011) The pathogenesis of rheumatoid arthritis. N Engl JMed.365:2205-19.

3.Klarenbeek NB, Kerstens PJ, Huizinga TW, Dijkmans BA, Allaart CF.(2010) recent advances in the management of rheumatoid arthritis. BMJ. 341:c6942.

4.Prajapati R, Plant D, Barton A.(2011) Genetic and genomic predictors of anti-TNFresponse.

Pharmacogenomics.12:1571-85.

5.Camen Castro-Villegas, Carlos PerezSanchez, Alejandro Escudero, IleanaFilipescuetai. (2015) circulating miRNA as potential biomarkers of therapy effectiveness in rheumatoid arthritis patientstrated with anti-TNF $\alpha$. Arthritis Research \& therapy.17:49.13075-015-0555.

6.Burska A, Boissinot M, Ponchel F. (2014) Cytokines as biomarkers in rheumatoid arthritis. Mediators Inflamm.545493.

7.Niu X, Chen G.(2014) Clinical biomarkers and pathogenic-related cytokines in rheumatoid arthritis. J Immunol Res.698192.

8.Zivojinovic SM, Pejnovic NN, SefikBukilica MN, Kovacevic LV, Soldatovic II, Damjanov NS.(2012) 
Tumor necrosis factor blockade differentially affects innate inflammatory and Th17 cytokines in rheumatoid arthritis.JRheumatol. 39:18-21.

9.Hussein YM, Mohamed RH, Pasha HF, El-Shahawy EE, Alzahrani SS.(2011) Association of tumor necrosis factor alpha and its receptorpolymorphisms with rheumatoid arthritis in female patients. Cell Immunol. 271:192-6.

10.Hussein YM, Alhazmi AS, Tawfik EA, Khalil SM, Alzahrani SS et al.(2014) IL-4R $\alpha$, TNF- $\alpha$ receptor, and CD4 enhancer genes polymorphisms in rheumatoid arthritis Saudi female patients. IOSR journal of Dental and Medical Sciences. 13:8; 71-82.

11.Sennikov SV, Vasilyev FF, Lopatnikova JA, shkaruba NS, Silkov AN.(2014) Polymorphisms un the tumor necrosis factor receptor genes affect the expression levels of membrane bound type 1 and type 2 receptors. Mediators Inflamm. 10.1155/4014/ 745909,11pages.

12.Mukai Y, Nakamura T, Yoshikawa M, et al.(2010) Solution of the structure of the TNF-TNFR2 complex.Science Signaling.3(148, article ra83).

13.Cabal-Hierro L, Lazo PS. (2012) Signal transduction by tumor necrosis factor receptors. Cellular Signalling.24 (6):1297-1305.

14.Ilkov AN, Sennikova NS, Goreva EP, Lopatnikova YA, Sennikov SV.(2012) Production of TNF- $\alpha$ and IL- $1 \beta$ by peripheral blood mononuclear cells in carriers of different allele variants of the gene. Bulletin of Experimental Biology and Medicine.153(1):68-71. 15.Swierkot J, Bogunia - Kubik K, Nowak B, Bialowas K, Korman L, Gebura K, Kolossa K, Jeka S, Wiland P. (2015) Analysis of associations between polymorphisms within genes coding for tumor necrosis factor (TNF) alpha and TNF receptors and responsiveness to TNF-alpha blockers in patients with rheumatoid arthritis. Joint Bone Spine.82(2):94-9.

16.Barton A, John S, Ollier WE, Silman A, Worthington J.(2001) Association between rheumatoid arthritis and polymorphism of tumor necrosis factor receptor II, but not tumor necrosis factor receptor I, in Caucasians. Arthritis Rheum.44:615.

17.Dieudé P, Petit E, Cailleau-Moindrault S, Osorio J, Pierlot C, Martinez M, et al.(2002) Association between tumor necrosis factor receptor II and familial, but not sporadic, rheumatoid arthritis: evidence for genetic heterogeneity. Arthritis Rheum.46:2039-44

18.Shibue T, Tsuchiya N, Komata $\mathrm{T}$, Matsushita M, Shiota M, Ohashi J, et al.(2000) Tumor necrosis factor alpha 5'-flanking region, tumor necrosis factor receptor II, and HLA-DRB1 polymorphisms in Japanese patients with rheumatoid arthritis. Arthritis Rheum.43:753-7.

\section{How to cite this article:}

Wasnaa J. Mohammed, Mohammed Sh. Jabur, Nizar Ab. Jasim and Basim Sh. 2016. Validity of TNFRII Polymorphism in Susceptibility and Severity of Rheumatoid Arthritis Iraqi Patients. Int.J.Curr.Microbiol.App.Sci. 5(4): 969-975. doi: http://dx.doi.org/10.20546/ijcmas.2016.504.110 